\title{
Rendimento de grãos de híbridos de milho em duas densidades de plantas com e sem a retirada dos perfilhos
}

\author{
Grain yield of maize hybrids at two plant densities with and without tillers removal
}

\author{
Luís Sangoi ${ }^{\mathrm{I}}$ Amauri Schmitt ${ }^{\mathrm{II}}$ Alexandre Saldanha ${ }^{\mathrm{III}}$ Ciro Franco Fiorentin ${ }^{\mathrm{III}}$ \\ Anderson José Pletsch ${ }^{\mathrm{III}}$ Jefferson Vieria ${ }^{\mathrm{III}}$ Maxciel Alcimar Gattelli ${ }^{\mathrm{II}}$
}

\section{RESUMO}

O milho não possui um mecanismo efetivo de compensação de espaços vazios na lavoura. Desse modo, híbridos perfilhadores podem ser mais eficientes no aproveitamento dos recursos ambientais, principalmente sob baixas populações de plantas. Este trabalho foi conduzido com o objetivo de avaliar o desempenho agronômico de híbridos de milho cultivados em duas densidades de plantas, com e sem a presença de perfilhos. O ensaio foi implantado em Lages, Santa Catarina, nos anos agrícolas de 2005/2006 e 2006/2007. Foram avaliados três híbridos: AS1560, PENTA e P30F53. Cada híbrido foi cultivado nas densidades de 4,0 e $7,0 \mathrm{pl} \mathrm{m} \mathrm{m}^{-2}$, mantendo-se os perfilhos produzidos até o final do ciclo ou removendo-os quando as plantas estavam com nove folhas expandidas. Foram determinados a percentagem de plantas perfilhadas em quatro estádios fenológicos da cultura, $o$ rendimento de grãos e os componentes do rendimento. Os híbridos P30F53 e AS 1560 perfilharam mais que o PENTA na

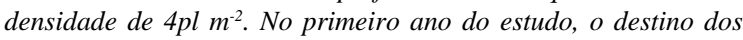
perfilhos não interferiu sobre o rendimento de grãos. Em 2006/ 2007, a manutenção dos perfilhos propiciou maior rendimento de grãos que a sua remoção para todos os híbridos avaliados, na densidade de $4 \mathrm{pl} \mathrm{m}^{-2}$. Os resultados obtidos no trabalho demonstraram que a remoção dos perfilhos não traz benefícios ao desempenho agronômico do milho e que a sua manutenção pode incrementar o rendimento de grãos quando a lavoura é conduzida com baixas densidades de plantas.

Palavras-chave: Zea mays, perfilhamento, população de plantas, rendimento de grãos.

\section{ABSTRACT}

Maize does not have an effective mechanism to compensate empty spaces in the field. Therefore, tillering hybrids may be more efficient to use environmental resources, especially under low plant populations. This reserach was carried out aiming to evaluate the agronomic performance of maize hybrids grown at two plant densities, with and without tiller's presence. The experiment was set in Lages, SC, Brazil, during the 2005/ 2006 and 2006/2007 growing seasons. Three hybrids were tested: AS 1560, Penta and P30F53. Each hybrid was evaluated at the densities of 4 and $7 \mathrm{pl} \mathrm{m} \mathrm{m}^{-2}$, keeping tillers until harvest or removing them when the crop had nine expanded leaves. The percentage of plants with tillers at four growth stages, grain yield and yield components were assessed. Hybrids P30F53 and AS 1560 produced more tillers than Penta at the density of $4 \mathrm{pl} \mathrm{m} \mathrm{m}^{-2}$. Tillers destiny did not affect grain yield during the first growing season. In 2006/2007 tiller maintenance promoted higher grain yield than tiller removal for all hybrids at the lower plant density. The results of this work showed that tiller removal does not enhance maize agronomic performance. Furthermore, they demonstrated that tiller maintenance may increase grain yield when maize is grown under low plant densities.

Key words: Zea mays, tillering, plant population, grain yield.

\section{INTRODUÇÃO}

As principais culturas de lavoura apresentam uma faixa de população de plantas que maximiza o rendimento de grãos. Nas espécies da família das poáceas, a definição da densidade ótima depende da quantidade de sementes utilizada na semeadura e da capacidade das plantas ocuparem os espaços vazios, produzindo perfilhos. Assim, o número ideal de

IDepartamento de Agronomia, Universidade do Estado de Santa Catarina (UDESC), CP 281, 88520-000, Lages, SC, Brasil. E-mail: a2ls@cav.udesc.br. Autor para correspondência.

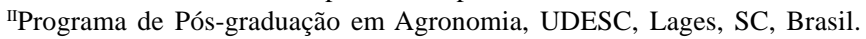

${ }^{\text {IIIC } C u r s o ~ d e ~ A g r o n o m i a, ~ U D E S C, ~ L a g e s, ~ S C, ~ B r a s i l . ~}$ 
indivíduos por área nesta família depende da plasticidade da espécie em ocupar os espaços deixados entre uma planta e outra pelo perfilhamento (MUNDSTOCK, 1999).

A emissão, o desenvolvimento e a sobrevivência dos perfilhos são importantes para muitas Poaceas, pois estas estruturas fazem parte dos componentes do rendimento e funcionam como supridoras de assimilados ao colmo principal (ALMEIDA, 1998). Nas espécies em que isso é comum, tais como o trigo e o arroz, os perfilhos são estruturas benéficas, pois aumentam o número de espigas e panículas por área e contribuem para o incremento do rendimento de grãos (MEROTTO JR., 1995).

A densidade de plantas interfere na quantidade e na qualidade de radiação interceptada pelo dossel (ANDRADE et al., 2000; MADDONI et al., 2001). O aumento na população reduz a quantidade de radiação na faixa do vermelho $(\mathrm{V})$ que chega aos extratos inferiores do cultivo e aumenta na faixa do vermelho extremo (Ve). A redução na relação V/Ve promovida pelo adensamento limita o perfilhamento das Poaceas (TAIZ \& ZEIGER, 2002).

Altas produtividades de grãos de milho só podem ser obtidas com o perfeito ajuste do número de plantas por unidade de área. O número ideal de plantas por área é determinado de acordo com a cultivar utilizada, a forma de uso do milho, os níveis de fertilidade do solo e de adubação prevista e a disponibilidade hídrica durante o ciclo (MUNDSTOCK \& SILVA, 2005).

A grande dependência do milho em população de plantas para maximizar o rendimento deve-se ao fato de ele não possui um mecanismo de compensação de espaços tão eficiente quanto outras espécies da família das poáceas (SILVA et al., 2006). Esta característica decorreu do processo de seleção a que o milho foi submetido durante a sua evolução do teosinto, o qual priorizou a dominância apical, reduzindo o número de ramificações laterais e concentrando toda a energia da planta no colmo principal (SANGOI \& SALVADOR, 1996; DOEBLEY, 1997).

Historicamente, os perfilhos têm sido considerados estruturas indesejáveis na lavoura de milho, pois normalmente não produzem espigas e quando o fazem estas são pequenas e imperfeitas. Além disso, os perfilhos aumentam a quantidade de massa seca que passa pela colheitadeira, o que pode dificultar a colheita (NAFZINGER, 2006).

Por outro lado, alguns híbridos comerciais liberados recentemente no mercado apresentam como características marcantes o alto potencial produtivo e a grande capacidade de emissão de perfilhos. A associação destes dois atributos sugere que os perfilhos não são prejudiciais à cultura do milho, assim eles podem contribuir para o rendimento de grãos indiretamente, fornecendo fotoassimilados ao colmo principal, ocupando espaços vazios na lavoura e aumentando a área foliar.

Assim, cultivares perfilhadoras de milho podem ser mais eficientes no aproveitamento dos recursos ambientes, principalmente sob baixas populações de plantas. Esta resposta é desejável quando a ocorrência de baixas densidades decorre de fatores adversos que prejudicam a emergência e o desenvolvimento inicial das plantas, tais como velocidade excessiva na semeadura e profundidade de semeadura inadequada.

O estudo dos fatores bióticos e abióticos que interferem sobe o perfilhamento do milho pode favorecer a obtenção de cultivares que melhor explorem os recursos disponíveis do ambiente. Este trabalho foi conduzido com o objetivo de quantificar o impacto da remoção ou da manutenção dos perfilhos sobre o desempenho agronômico de híbridos de milho em duas densidades de plantas.

\section{MATERIAL E MÉTODOS}

O experimento foi conduzido a campo durante os anos agrícolas de 2005/2006 e 2006/2007. A área experimental situa-se a $27^{\circ} 50^{\prime} 35^{\prime \prime}$ de latitude sul e $50^{\circ} 29^{\prime} 45^{\prime \prime}$ de longitude oeste e altitude de $849 \mathrm{~m}$. O clima da região é do tipo $\mathrm{Cfb}$, mesotérmico, com verões brandos, temperaturas médias do mês mais quente inferiores a $22^{\circ} \mathrm{C}$ e precipitações pluviais bem distribuídas. O solo da área experimental é classificado como NITOSSOLO VERMELHO Distrófico típico (EMBRAPA, 1999).

Foram testados três híbridos simples de milho: AS 1560, P30F53 e PENTA, todos de ciclo precoce. Os híbridos foram cultivados nas densidades de quatro (baixa) e sete (alta) pl m². Em cada combinação de híbrido e densidade, realizou-se a retirada ou a manutenção dos perfilhos. A retirada dos perfilhos foi feita quando o colmo principal estava no estádio V9 (nove folhas expandidas) da escala de RITCHIE et al. (1993).

O delineamento experimental foi de blocos casualizados, dispostos em parcelas sub-subdivididas, com quatro repetições. Os híbridos foram testados na parcela principal, as densidades de plantas nas subparcelas e a manutenção ou retirada dos perfilhos nas sub-subparcelas. Cada sub-subparcela foi composta por quatro linhas com sete metros de comprimento, tendo como área útil as duas linhas 
centrais, excluindo-se $0,5 \mathrm{~m}$ da extremidade de cada linha.

O experimento foi instalado no dia 21 de outubro dos dois anos de cultivo, no sistema de semeadura direta, sob cobertura de inverno de aveia preta e ervilhaca. O espaçamento entre linhas foi de $0,7 \mathrm{~m}$. Foram aplicados durante a semeadura, com base nos resultados da análise de solo e nas recomendações da COMISSÃO DE FERTILIDADE DO SOLO RS-SC (2004) para produção de $12.000 \mathrm{~kg} \mathrm{ha}^{-1}$ de milho, $30 \mathrm{~kg}$ de $\mathrm{N}$, 205kg de $\mathrm{P}_{2} \mathrm{O}_{5}$ e $100 \mathrm{~kg}$ de $\mathrm{K}_{2} \mathrm{O}$ por hectare. A adubação nitrogenada de cobertura foi feita utilizando duas doses de $100 \mathrm{~kg} \mathrm{ha}^{-1}$ de $\mathrm{N}$, realizadas quando as plantas se encontravam nos estádios V4 (quatro folhas expandidas) e V8 (oito folhas expandidas) da escala de RITCHIE et al. (1993).

O controle de plantas daninhas foi efetuado com duas aplicações de herbicida. A primeira foi feita em pré-emergência, no dia da semeadura, com uma mistura de produto atrazina e s-metolaclor $(1.480+$ $1.160 \mathrm{~g}$ de i.a. ha $\left.^{-1}\right)$. A segunda foi efetuada em pósemergência quando as plantas se encontravam no estádio V3, utilizando o produto nicosulfuron (56g de i.a. ha $\left.^{-1}\right)$. Também foram realizadas duas aplicações preventivas do inseticida lufenuron (15g de i.a. ha-1) com jato dirigido, para controle da lagarta do cartucho (Spodoptera frugiperda), quando as plantas estavam nos estádios V5 (cinco folhas expandidas) e V10 (dez folhas expandidas) da escala de RITCHIE et al. (1993).

Nas sub-subparcelas onde os perfilhos foram mantidos, foi avaliada a percentagem de plantas perfilhadas nos estádios V9 e V15 da escala de RITCHIE et al. (1993), na floração (estigmas visíveis e pendões com deiscência de pólen) e na colheita, que ocorreu quando todas as folhas estavam senescidas e a umidade dos grãos era de 18 a 22\%. As espigas produzidas nos colmos principais e nos perfilhos foram colhidas separadamente, para que se pudesse avaliar a contribuição dos perfilhos na definição da produtividade global por área. Além do rendimento de grãos, determinou-se o número de grãos produzidos por metro quadrado e o peso de 1000 grãos.

Os dados obtidos foram avaliados estatisticamente por meio programa SAS, por meio da análise de variância, utilizando-se o teste F. Quando alcançada significância estatística, as médias de cada tratamento foram comparadas entre si pelo teste de Tukey. Para todas as análises adotou-se o nível de significância de $5 \%(P<0,05)$.

\section{RESULTADOS E DISCUSSÃO}

Nos dois anos de cultivo, a percentagem de plantas perfilhadas foi afetada pela interação entre densidades e híbridos (Figura 1). Tanto em 2005/2006 quanto em 2006/2007, os híbridos P 30F53 e AS 1560 apresentaram maior percentagem de plantas perfilhadas do que o Penta na densidade de $4 \mathrm{pl} \mathrm{m}^{-2}$.

Na safra 2005/2006 (Figura 1A), os híbridos P30F53 e AS1560 mantiveram mais de 88\% de plantas afilhadas até a floração, na densidade de quatro plantas $\mathrm{m}^{-2}$. No momento da colheita, os valores registrados pela menor população de plantas caíram para $71 \%$ e $30 \%$, respectivamente, para o P30F53 e o AS1560. O comportamento de percentagem de plantas afilhadas ao longo do ciclo indica que, sob condição favorável, a maioria dos perfilhos mantém-se vivo até o florescimento. A partir deste momento, as plantas concentram suas energias no armazenamento de fotoassimilados nos grãos, o que provavelmente contribuiu para aumentar a mortalidade dos perfilhos (SCHMITT, 2008).

No primeiro ano de cultivo, a percentagem de plantas perfilhadas do híbrido P30F53 não diferiu entre densidades até o início do pendoamento. O híbrido AS1560 reduziu a percentagem de plantas perfilhadas quando submetido à maior densidade de cultivo já na primeira época de avaliação. Isso demonstra que o perfilhamento do híbrido AS1560 esteve diretamente relacionado à densidade desde 0 estádio V9, enquanto que no híbrido P30F53 o efeito da população somente foi evidenciado na colheita. A população de plantas exerceu um efeito menos pronunciado sobre a percentagem de plantas afilhadas do PENTA do que dos demais híbridos. Com exceção do estádio V9, não houve diferença significativa para esta variável entre as densidades de $4 \mathrm{e} 7 \mathrm{pl} \mathrm{m}^{-2}$. Este híbrido demonstrou ser menos predisposto ao perfilhamento que os outros dois, tanto na baixa quanto na alta densidade.

No segundo ano de cultivo, os valores numéricos para percentagem de plantas perfilhadas foram menores que no primeiro, não ultrapassando $80 \%$. Em 2005/2006, a percentagem máxima de plantas perfilhadas foi superior a 97\%. Em 2006/2007, o híbrido P30F53 apresentou maior percentagem de plantas perfilhadas que os demais híbridos na densidade de

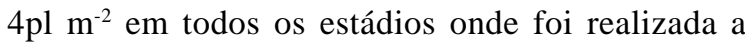
avaliação. Outra característica observada na safra 2006/ 2007 foi de que o efeito supressivo do aumento da população sobre a percentagem de plantas afilhadas foi mais acentuado para o híbrido mais propenso ao perfilhamento (P30F53) em V9 e na floração.

O comportamento da percentagem de plantas afilhadas evidencia que os híbridos predispostos a perfilhar respondem negativamente ao aumento na densidade, produzindo menos plantas com 


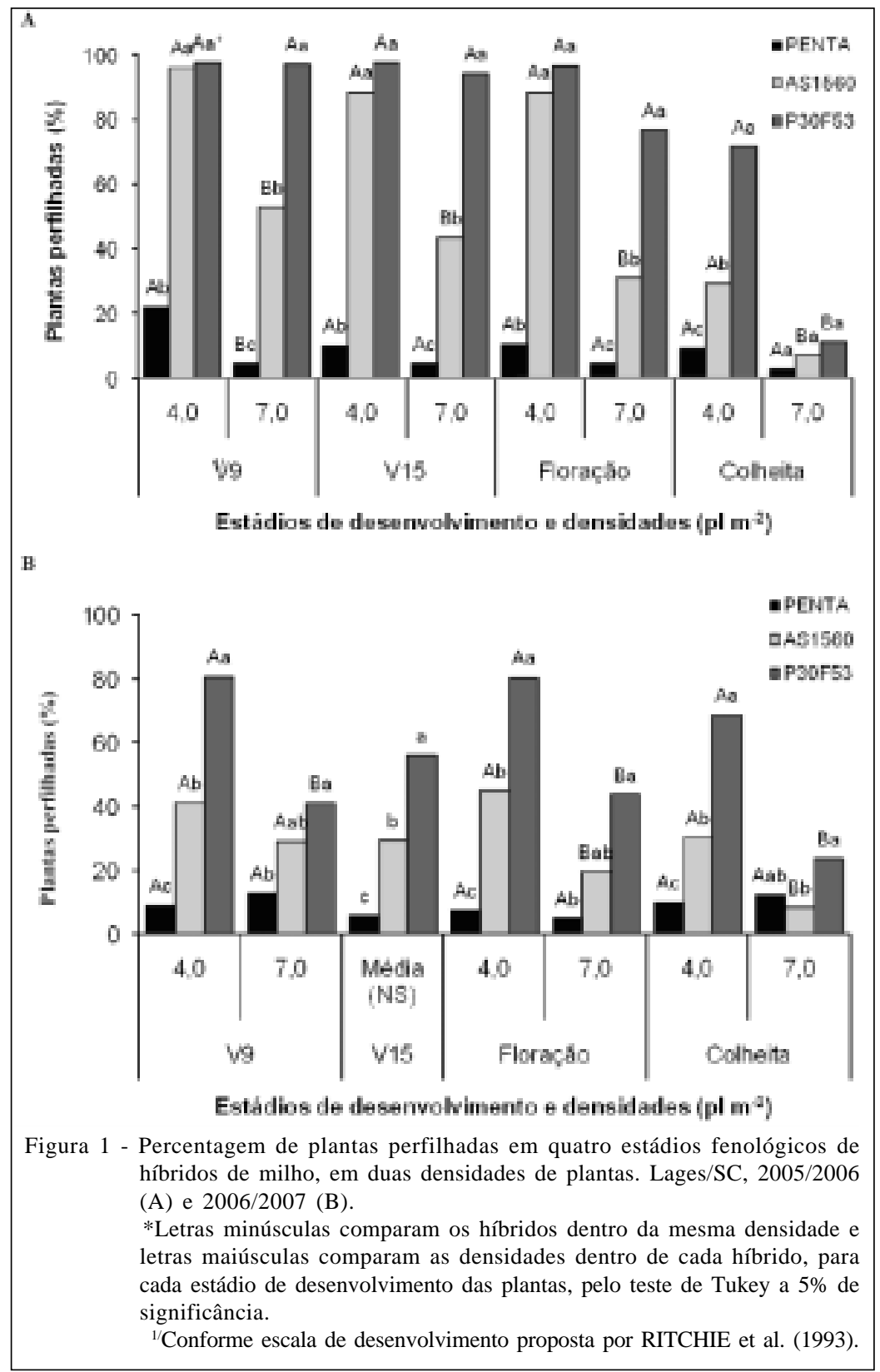

perfilhos, corroborando as observações feitas por SANGOI et al. (2007a). A menor densidade possivelmente produziu mais perfilhos devido à menor competição intra-específica por água, luz e nutrientes, o que aumentou a produção de perfilhos na população de $4 \mathrm{pl} \mathrm{m}^{-2}$, levando a um ajuste na densidade final de colmos (colmo principal + perfilhos) por unidade de área com incremento no perfilhamento. Este comportamento é comum nas espécies das poáceas e foi registrado por ALMEIDA et al. (2000) na cultura do trigo.

Em 2005/2006, o rendimento de grãos foi afetado pela interação entre híbridos e densidades de plantas, oscilando entre 4.169 e $11.927 \mathrm{~kg} \mathrm{ha}^{-1}$ (Tabela 1). Os híbridos P30F53 e Penta foram mais produtivos que híbrido AS1560 nas duas densidades. O incremento na população de quatro para sete plantas $\mathrm{m}^{-2}$ aumentou o rendimento de grãos dos híbridos P30F53 e Penta reduziu o do AS1560. Esta redução verificada no rendimento de grãos do híbrido AS1560 na maior densidade de plantas deveu-se a um problema de má formação de espigas e de assincronia entre os florescimentos masculino e feminino, que ocorreu em maior intensidade nesta densidade, características que reduziram o número de grãos por espiga e por metro quadrado deste híbrido na maior densidade (Tabela 2). 
Tabela 1 - Rendimento de grãos de híbridos de milho em duas densidades de plantas, na média da condição com e sem perfilhos. Lages/SC, 2005/2006

\begin{tabular}{llcc}
\hline & & & \\
Densidade de plantas $\left(\mathrm{pl} \mathrm{m}^{-2}\right)$ & AS1560 & P30F53 & PENTA \\
\hline 4 & A $6.035 \mathrm{~b}^{*}$ & B $9.704 \mathrm{a}$ & B 10.179 a \\
7 & B $4.169 \mathrm{~b}$ & A $11.562 \mathrm{a}$ & A 11.927 a \\
\hline
\end{tabular}

*Médias não seguidas pela mesma letra minúscula na linha e maiúscula na coluna diferem significativamente pelo teste de Tukey a 5\% de significância.

Neste primeiro ano de cultivo, o número de grãos produzidos por área foi o componente mais associado com o rendimento de grãos (Tabela 2), sendo mais alto na densidade de $7 \mathrm{pl} \mathrm{m}^{-2}$ que na de $4 \mathrm{pl} \mathrm{m}^{-2}$ para os híbridos P30F53 e PENTA, o que contribuiu para os seus melhores desempenhos agronômicos no estande mais adensado.

O destino dos perfilhos não interferiu significativamente sobre o rendimento de grãos em 2005/2006. Isso é um indicativo de que o perfilhamento não prejudicou a produtividade da cultura do milho. Esta informação corrobora as ponderações de NAFTINGER (2006) de que o desenvolvimento de perfilhos é um aspecto normal da fisiologia da planta de milho, não reduzindo a sua produtividade, desde que não tenha sido causado por danos de insetos, injúrias mecânicas ou incidência de doenças.

Na safra 2006/2007, o rendimento de grãos foi afetado pela interação tripla entre híbrido, densidade e destino dos perfilhos, variando entre $7.731 \mathrm{e} 11.788 \mathrm{~kg}$ $\mathrm{ha}^{-1}$. Na densidade de quatro plantas $\mathrm{m}^{-2}$, o P3053 foi mais produtivo que os demais híbridos, independentemente da presença ou remoção dos perfilhos (Tabela 3). Isso evidencia que o P 30F53 apresentou maior capacidade de compensação de espaços do que os demais híbridos quando cultivado em baixas densidades populacionais. Na densidade de 7,0pl m², os híbridos P 30F53 e Penta não diferiram entre si e foram mais produtivos que o AS 1560.

A manutenção dos perfilhos propiciou a obtenção de maior rendimento de grãos do que a sua remoção em V9 para todos os híbridos avaliados, na densidade de quatro plantas $\mathrm{m}^{-2}$ (Tabela 3). Nesta população de plantas, os perfilhos contribuíram com $1.148 \mathrm{~kg} \mathrm{ha}^{-1}$ para a produtividade final, na média dos três híbridos (Tabela 4). Por outro lado, na densidade de sete plantas $\mathrm{m}^{-2}$, a presença dos perfilhos não incrementou estatisticamente a produtividade do híbrido PENTA, o qual externou menor percentagem de plantas afilhadas na colheita (Figura 1B). Estes dados demonstram que os perfilhos não interferiram negativamente sobre o desempenho agronômico da cultura, reforçando as ponderações feitas por SANGOI et al. (2007b) e SCHMITT (2008) de que a sua remoção, além de desnecessária, pode reduzir o rendimento de grãos. Isso ocorre principalmente com híbridos com

Tabela 2 - Componentes do rendimento de híbridos de milho em duas densidades de plantas, na média da condição com ou sem perfilhos. Lages/SC, 2005/2006.

\begin{tabular}{|c|c|c|c|}
\hline \multirow{2}{*}{ Densidade de plantas $\left(\mathrm{pl} \mathrm{m}^{-2}\right)$} & \multicolumn{3}{|c|}{--Híbridos-- } \\
\hline & AS1560 & P30F53 & PENTA \\
\hline \multirow{3}{*}{$\begin{array}{l}4 \\
7\end{array}$} & - & por área (n & 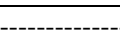 \\
\hline & A $1.147 c^{*}$ & B $2.320 \mathrm{~b}$ & B 2.755 a \\
\hline & A $1.583 \mathrm{~b}$ & A 3.413 a & A 3.410 a \\
\hline & & de 1000 grã & --- \\
\hline 4 & A 526 a & A 418 b & A 369 c \\
\hline 7 & B 263 b & В 339 а & A 350 a \\
\hline
\end{tabular}

* Médias não seguidas pela mesma letra minúscula na linha e maiúscula na coluna diferem significativamente pelo teste de Tukey a 5\% de significância.

Ciência Rural, v.39, n.2, mar-abr, 2009. 
Tabela 3 - Rendimento de grãos de híbridos de milho em duas densidades de plantas, com (C) e sem (S) a presença dos perfilhos. Lages/SC, 2006/2007.

\begin{tabular}{|c|c|c|c|c|c|c|}
\hline \multirow[b]{2}{*}{ 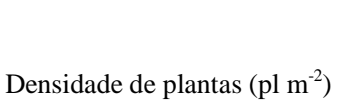 } & \multicolumn{2}{|c|}{-------------PENTA------------- } & \multicolumn{2}{|c|}{-------------AS1560------------- } & \multicolumn{2}{|c|}{-------------P30F53------------- } \\
\hline & S perfilho & C perfilho & S perfilho & C perfilho & S perfilho & C perfilho \\
\hline & \multicolumn{6}{|c|}{ Rendimento de grãos (kg ha $\left.{ }^{-1}\right)$} \\
\hline \multirow{2}{*}{4,0} & $\mathrm{~B}^{4 /}$ & $\mathrm{A}$ & $\mathrm{B}$ & $\mathrm{A}$ & $\mathrm{B}$ & $\mathrm{A}$ \\
\hline & B $8.248 b^{1 /}$ & B $9.629 \underline{b}^{2 /}$ & A 7.906 b & B $8.665 \underline{c}$ & B 9.205 a & B $10.665 \underline{a}$ \\
\hline \multirow{2}{*}{7,0} & A & A & B & A & $\mathrm{B}$ & A \\
\hline & $\mathrm{A}^{3 /} 11.492 \mathrm{a}$ & A $11.788 \underline{a}$ & A 7.731 b & A $9.597 \underline{b}$ & A 10.989 a & A $11.581 \underline{\mathrm{a}}$ \\
\hline
\end{tabular}

${ }^{1 /}$ Médias não seguidas pela mesma letra minúscula na linha, na condição sem afilhos, diferem significativamente pelo teste de Tukey a 5\% de significância.

${ }^{2 /}$ Médias não seguidas por mesma letra minúscula sublinhada na linha, na condição com afilhos, diferem significativamente pelo teste de Tukey a 5\% de significância.

${ }^{3 /}$ Médias não antecedidas por mesma letra maiúscula na coluna diferem significativamente pelo teste de Tukey a 5\% de significância.

${ }^{4 /}$ Médias não seguidas por mesma letra maiúscula sobrescrita, para cada híbrido e densidade de plantas, diferem significativamente pelo teste de Tukey a 5\% de significância.

alta capacidade de afilhamento, como, por exemplo ,o P30F53, e em baixas densidades de plantas, situação em que os perfilhos contribuíram com até $2.072 \mathrm{~kg} \mathrm{ha}^{-1}$ para o rendimento de grãos (Tabela 4).

\section{CONCLUSÕES}

Os híbridos de milho diferiram na capacidade de emissão de perfilhos, principalmente quando cultivados em baixas densidades de plantas. A remoção dos perfilhos não aumentou o rendimento de grãos do milho. Os perfilhos podem ser estruturas importantes para a compensação de espaços e incrementos no rendimento de grãos do milho quando a lavoura é implantada com baixas populações de plantas.

\section{AGRADECIMENTOS}

Ao Conselho Nacional de Desenvolvimento Científico e Tecnológico (CNPq), pelo auxílio financeiro ao projeto (processo $n^{\circ}$ 470202-2007-6), pela concessão da Bolsa de Produtividade em Pesquisa ao primeiro autor do trabalho e de iniciação científica aos acadêmicos do curso de graduação em Agronomia. À Coordenação de Aperfeiçoamento de Pessoal Docente de Ensino Superior (CAPES), pela concessão da Bolsa de Mestrado ao aluno do Programa de Pós-graduação em Agronomia.

Tabela 4 - Componentes do rendimento e rendimento de grãos dos perfilhos de três híbridos de milho em duas densidades de plantas. Lages, SC, 2006/2007.

\begin{tabular}{|c|c|c|c|c|}
\hline \multirow{2}{*}{ Densidade de plantas $\left(\mathrm{pl} \mathrm{m}^{-2}\right)$} & \multicolumn{4}{|c|}{ 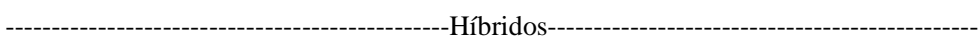 } \\
\hline & PENTA & AS1560 & P30F53 & Média \\
\hline & \multicolumn{4}{|c|}{ 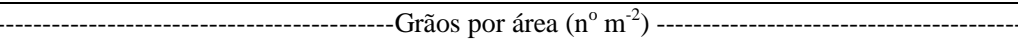 } \\
\hline 4,0 & 2.228 & 2.470 & 2.290 & B 2.214 \\
\hline 7,0 & 2.987 & 2.122 & 3.092 & A 2.850 \\
\hline Média & $2.608 a^{*}$ & $2.296 \mathrm{~b}$ & $2.691 \mathrm{a}$ & \\
\hline 4,0 & 389 & $\begin{array}{l}------P e s \\
371\end{array}$ & $\begin{array}{l}\text { (g) ----- } \\
391\end{array}$ & A 384 \\
\hline 7,0 & 374 & 344 & 349 & В 356 \\
\hline Média & 382 a & $358 \mathrm{~b}$ & $370 \mathrm{ab}$ & \\
\hline & & ndimento $\mathrm{C}$ & filhos (kg & \\
\hline 4,0 & 541 & 834 & 2.072 & A 1.148 \\
\hline 7,0 & 770 & 261 & 997 & В 676 \\
\hline Média & $655 \mathrm{~b}$ & $547 \mathrm{~b}$ & $1.534 \mathrm{a}$ & 912 \\
\hline
\end{tabular}

* Médias não seguidas pela mesma letra minúscula na linha e maiúscula na coluna diferem significativamente pelo teste Tukey a 5\% de significância.

Ciência Rural, v.39, n.2, mar-abr, 2009. 


\section{REFERÊNCIAS}

ALMEIDA, M.L. de. Modificação do afilhamento de trigo e aveia pela qualidade de luz. 1998. 121f. Tese (Doutorado em Fitotecnia) - Curso de Pós-graduação em Fitotecnia. Universidade Federal do Rio Grande do Sul.

ALMEIDA, M.L. de. et al. Determinação do momento da emissão de perfilhos de trigo usando suplementação com luz vermelha e luz vermelha extrema. Pesquisa Agropecuária Gaúcha, Porto Alegre, v.6, n.1, p.89-97, 2000.

ANDRADE, F. et al. Intercepted radiation at flowering and kernel number in maize. Agronomy Journal, Madison, v.92, n.1, p.92-97, 2000.

COMISSÃO DE FERTILIDADE DO SOLO-RS/SC. Recomendações de adubação e calagem para os estados do Rio Grande do Sul e Santa Catarina. Porto Alegre: SBCS-Núcleo Regional Sul, 2004. 400p.

DOBLEY, J. et al. The evolution of apical dominance in maize. Nature, Nova Yorque, v.386, n.2, p.485-488, 1997.

EMPRESA BRASILEIRA DE PESQUISA AGROPECUÁRIA Sistema brasileiro de classificação de solos. Brasília: EMBRAPA, 1999. 412p.

MADDONI, G.A. et al. Plant population density, row spacing and hybrid effects on maize canopy architecture and light attenuation. Field Crops Research, Amsterdan, v.71, n.2, p.183-193, 2001.

MEROTTO JUNIOR, A. Processo de afilhamento crescimento de raízes de trigo afetados pela resistência do solo. 1995. $114 \mathrm{f}$. Dissertação (Mestrado em Fitotecnia) - Programa de Pós-graduação em Agronomia, Universidade Federal do Rio Grande do Sul.

MUNDSTOK, C.M. Planejamento e manejo integrado da lavoura de trigo. Porto Alegre: UFGRS, 1999. 228p.
MUNDSTOCK, C.M.; SILVA, P.R.F. Manejo da cultura do milho para altos rendimentos de grãos. Porto Alegre: Evangraf, 2005. 51p.

NAFZINGER, E. Effect of tiller removal on corn yield. University of Illinois. Capturado em 23 Abr. 2006. On line. Disponível em: http://www.cropsci.uiuc.edu/research/rdc/ report98/rpt98-12html.

RITCHIE, S.W. et al. How a corn plant develops. Ames: Iowa State University of Science and Technology, 1993. 26p. (Special Report, 48).

SANGOI, L.; SALVADOR, R.J. Os primeiros passos na evolução do milho: um tema controvertido. Universidade \& Desenvolvimento, Florianópolis, v.3, n.2, p.33-70, 1996.

SANGOI, L. et al. Rendimento de grãos de híbridos de milho em duas densidades populacionais, cultivados com e sem a presença dos perfilhos. In. REUNIÃO TÉCNICA CATARINENSE DE MILHO E FEIJÃO, 4., 2007a, Concórdia, SC. Resumos expandidos... Chapecó: EPAGRI/CEPAF, 2007. 350p. p.149-153.

SANGOI, L. et al. Estádio de remoção dos perfilhos e desempenho agronômico do milho em duas épocas de semeadura. In. REUNIÃO TÉCNICA CATARINENSE DE MILHO E FEIJÃO, 4, 2007a, Concórdia, SC. Resumos expandidos... Chapecó: EPAGIR/CEPAF, 2007. 350p. p.139-145.

SILVA, P.R.F. et al. Arranjo de plantas e sua importância na definição da produtividade em milho. Porto Alegre: Evangraf, 2006. 64p.

SCHMITT, A. Perfilhamento em milho: processo benéfico ou prejudicial ao desenvolvimento da planta e ao rendimento de grãos? 2008. 95f. Dissertação (Mestrado em Produção Vegetal) - Programa de Pós-graduação em Agronomia, Universidade do Estado de Santa Catarina.

TAIZ, L.; ZEIGER, E. Plant physiology. 3.ed. Redwood City: B. Cummings, 2002. 476p. 